\title{
Neutrophils trigger a NF-KB dependent polarization of tumor- supportive stromal cells in germinal center B-cell lymphomas
}

\author{
Murielle Grégoire ${ }^{1,2,3}$, Fabien Guilloton ${ }^{1,2,3}$, Céline Pangault ${ }^{1,2,3,4}$, Frédéric \\ Mourcin 1,2,3, Phaktra Sok ${ }^{1,2,3,5}$, Maelle Latour ${ }^{3,4}$, Patricia Amé-Thomas ${ }^{1,2,3,4}$, Erwan \\ Flecher $^{6}$, Thierry Fest ${ }^{1,2,3,4}$ and Karin Tarte ${ }^{1,2,3,4}$ \\ 1 INSERM, UMR U917, Equipe Labellisée Ligue Contre le Cancer, Rennes, France \\ 2 Université Rennes 1, UMR917, Rennes, France \\ ${ }^{3}$ EFS Bretagne, Rennes, France \\ ${ }^{4} \mathrm{CHU}$ de Rennes, Pôle Biologie, Rennes, France \\ ${ }^{5} \mathrm{CHU}$ de Rennes, Service de Médecine de L'enfant et de L'adolescent, Rennes, France \\ ${ }^{6} \mathrm{CHU}$ de Rennes, Service de Chirurgie Thoracique et Cardiovasculaire, Rennes, France \\ Correspondence to: Karin Tarte, email: karin.tarte@univ-rennes 1.fr
}

Keywords: B-cell lymphoma, tumor microenvironment, cell interaction, cell differentiation, lymph node

Received: April 21, 2015 Accepted: April 23, $2015 \quad$ Published: May 12, 2015

This is an open-access article distributed under the terms of the Creative Commons Attribution License, which permits unrestricted use, distribution, and reproduction in any medium, provided the original author and source are credited.

\section{ABSTRACT}

Both tumor-associated neutrophils (TAN) and cancer-associated fibroblasts (CAFs) display specific phenotypic and functional features and contribute to tumor cell niche. However, their bidirectional crosstalk has been poorly studied, in particular in the context of hematological malignancies. Follicular lymphomas (FL) and diffuse large B-cell lymphomas (DLBCL) are two germinal center-derived lymphomas where various cell components of infiltrating microenvironment, including TAN and CAFs, have been demonstrated to favor directly and indirectly malignant B-cell survival, growth, and drug resistance. We show here that, besides a direct and contactdependent supportive effect of neutrophils on DLBCL B-cell survival, mediated through the BAFF/APRIL pathway, neutrophils and stromal cells cooperate to sustain FL B-cell growth. This cooperation relies on an overexpression of IL-8 by lymphoma-infiltrating stromal cells that could thereafter efficiently promote neutrophil survival and prime them to neutrophil extracellular trap. Conversely, neutrophils are able to activate stromal cells in a NF-KB-dependent manner, inducing their commitment towards an inflammatory lymphoid stroma phenotype associated with an increased capacity to trigger malignant B-cell survival, and to recruit additional monocytes and neutrophils through the release of CCL2 and IL-8, respectively. Altogether, a better understanding of the lymphoma-supporting effects of neutrophils could be helpful to design new anti-tumor therapeutic strategies.

\section{INTRODUCTION}

Tumorigenesis is widely recognized as a noncell autonomous process depending on the continuous active crosstalk between malignant cells and various stromal and immune cell subsets of their surrounding microenvironment. Tumor infiltrating neutrophils (TAN) have initially received less attention than their macrophage counterpart (TAM) until the demonstration that they could persist within inflamed tissues where they exhibit both phenotypic and functional heterogeneity, including the production of a wide range of cytokines and chemokines $[1,2]$. TAN have been recently shown to exert both proand antitumor activities, including triggering of genomic instability, angiogenesis, immunosuppression, and tumor cell metastasis on the one hand versus direct cytotoxic 
effect and recruitment or activation of other effectors of innate and adaptive antitumor immunity on the other hand [3]. In turn, TAN recruitment and polarization are triggered by tumor cell-derived signals [4, 5]. Cancerassociated fibroblasts (CAFs) also contribute to tumorsupportive cell niche and have been shown to display tumor-specific transcriptomic, phenotypic, and functional features compared to normal tissue fibroblasts [6]. CAFs could support directly tumor cell survival, growth, metastasis, and drug resistance but they have also been involved in reshaping tumor microenvironment. Resident mesenchymal stromal cells (MSCs) are believed to be the major precursors of CAFs in situ and to acquire their tumor promoting properties after exposition to tumorderived activating stimuli. Whereas their impact on neutrophil activation remains controversial, bone marrow (BM)-MSCs have been repeatedly shown to sustain neutrophil survival, in particular following activation by inflammatory stimuli and TLR ligands $[7,8]$. IL-6 was proposed as the underlying molecular effector for this stroma-dependent anti-apoptotic activity. Recently, gastric cancer-derived MSCs have been specifically shown to promote neutrophil chemotaxis, survival, and activation through an IL-6/STAT-3 pathway [9]. However, few data are available concerning reciprocal interactions between TAN and CAFs in solid and hematological malignancies.

Follicular lymphoma (FL) and diffuse large B-cell lymphomas (DLBCL) result from the malignant transformation of germinal center (GC) B cells and are the two most frequent B-cell non-Hodgkin's lymphomas [10]. Both FL and DLBCL are generally disseminated diseases with frequent involvement of the BM that represents an ectopic supportive cell niche where CAFs display a specific gene expression profile (GEP) [11]. Transcriptomic signatures reflecting specific features of tumor microenvironment were shown to predict patient survival in FL and DLBCL $[12,13]$. Phenotypic and functional alterations of infiltrating $\mathrm{T}$ cells and TAM have been described in both diseases [14, 15]. Furthermore, stromal cells prevent lymphoma B-cell apoptosis in vitro [16, 17] through various contact-dependent and independent mechanisms including the production of B cell-activating factor (BAFF) [18]. BAFF and a proliferation-inducing ligand (APRIL) are closely related ligands of the TNF superfamily and have been shown to trigger lymphoma B-cell survival through their receptors BAFFR, TACI, and BCMA [19, 20]. Activated neutrophils are well known producers of soluble BAFF [21] and are supposed to trigger the survival and differentiation of normal B cells into immunoglobulin-producing plasma cells [22]. In addition, a novel subset of BAFFand APRIL-producing neutrophils able to stimulate immunoglobulin class switching, somatic hypermutation, and production by marginal zone B cells has been recently described in spleen [23] even if these results are disputable [24]. Whereas neutrophils are largely excluded from lymph nodes (LN) in steady state conditions, they could enter inflamed lymphoid organs and modulate adaptive immune response $[25,26]$. Interestingly, DLBCL TAN overexpress APRIL in situ allowing its accumulation on tumor B cells via proteoglycan binding [27]. Accordingly, the neutrophil to lymphocyte ratio in blood is an independent prognostic factor in patients with DLBCL [28]. However, despite these promising results, functional interactions between neutrophils and malignant $\mathrm{B}$ cells remain to be explored.

The potential role of TAN and stromal cells in B-cell lymphomagenesis and the emerging field of stroma-neutrophil interaction led us to investigate whether these two cell subsets establish a bidirectional crosstalk in the context of B-cell lymphomas. We have previously demonstrated that MSCs obtained from FL-infiltrated BM (FL-MSCs) produce higher level of CCL2 compared to BM-MSCs from healthy donors (HD-MSCs) in association with increased monocyte recruitment and polarization into TAM-like cells [11]. We explored here the interplay between malignant $B$ cells, stroma, and neutrophils. We demonstrated that FL-MSCs overexpressed IL-8 and triggered peripheral blood neutrophil recruitment. Moreover neutrophils and stromal cells cooperated to support malignant B-cell growth, owing to both a protection of neutrophils from spontaneous apoptosis, and an activation of stromal cells that acquired an inflammatory lymphoid stroma phenotype in contact with neutrophils. Finally, this crosstalk was associated with an activation of NF- $\mathrm{BB}$ pathway in stromal cells that sensitize neutrophils to neutrophil extracellular trap (NET) formation.

\section{RESULTS}

\section{Neutrophils directly sustain malignant B-cell growth}

We first decided to test whether neutrophils directly modified the growth of GC-derived lymphoma B-cell lines. Purified resting neutrophils did not display any cytotoxic effect towards malignant B cells but were conversely able to reverse serum deprivation-induced growth arrest of RL and SUDHL4 in a dose-dependent manner (Figure 1A). Similar results were obtained with DOHH2 (data not shown). This supportive effect was associated with a decreased B-cell apoptosis (Figure 1B). Interestingly, separation of B cells and neutrophils by a 0.4- $\mu \mathrm{m}$ transwell filter completely abrogated lymphomapromoting activity of neutrophils, indicating a key role for direct cell contact (Figure 1C). In agreement, whereas RL and SUDHL4 expressed BAFFR, TACI, BCMA and the APRIL co-receptor syndecan-4, addition of soluble BAFF or APRIL did not increase malignant B-cell growth (data not shown). However, circulating 
A
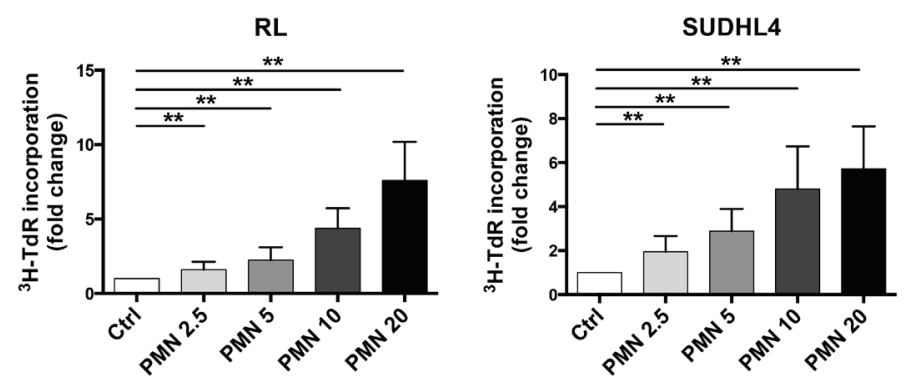

B

RL

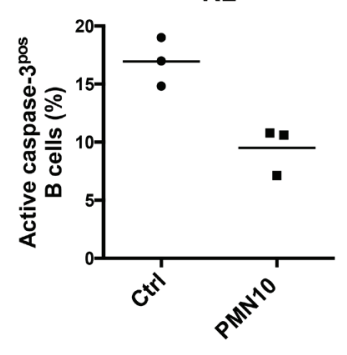

C
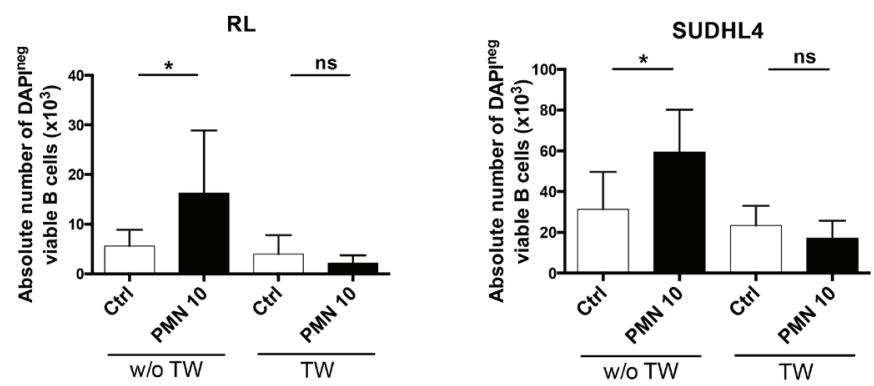

$\mathrm{D}$

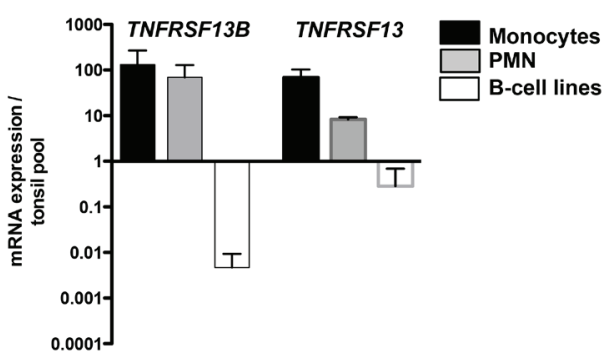

E
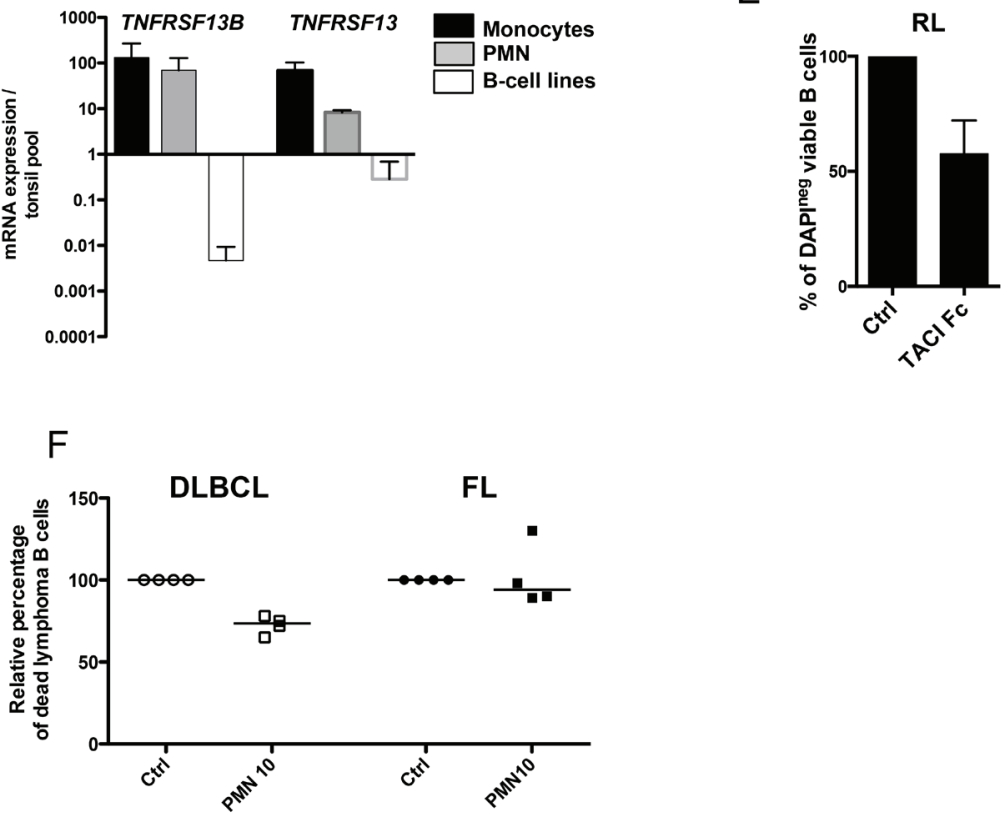

Figure 1: Neutrophils directly sustain the growth of malignant B-cell lines. (A) GC-derived B cell lines were cultured in low serum concentration alone $(\mathrm{Ctrl})$ or in the presence of different ratios of neutrophils (PMN)/B cells (2.5/1, 5/1, 10/1 or 20/1). Cell growth was evaluated by tritiated thymidine incorporation $\left({ }^{3} \mathrm{HTdR}\right)$ at day 2 for RL (left) and day 3 for SUDHL4 (right). B cell alone proliferation was arbitrary assigned to 1 . Results represent the mean $\pm \mathrm{SD}$ from 10 experiments. $* * P<0.01$. (B) Apoptosis was evaluated at day 1 on RL co-cultured or not with neutrophils as the percentage of active caspase- $3^{\text {pos }}$ cells gated on CD19/CD20 ${ }^{\text {pos }} \mathrm{CD} 15^{\text {neg }} \mathrm{B}$ cells. $(\mathbf{C}) \mathrm{GC}$ derived B cell lines were separated or not from neutrophils by a transwell (TW) insert, and B-cell growth was evaluated by determining the absolute number of DAPI ${ }^{\text {neg }} \mathrm{CD} 19 / \mathrm{CD} 20^{\text {pos }} \mathrm{CD} 6 \mathrm{~b}^{\text {neg }}$ viable B cells using FlowCount beads at day 3 for RL (left) and day 4 for SUDHL4 (right). Results represent the mean \pm SD from 6 experiments. $* P<0.05$. (D) TNFRSF13B and TNFRSF13 gene expression were compared in purified CD14 ${ }^{\text {pos }}$ monocytes ( $\left.n=3\right)$, purified CD15 pos PMN ( $\left.=3\right)$, and RL, SUDHL4 and DOHH2 B-cell lines. The arbitrary value of 1 was assigned to a pool of five whole tonsil cells. Bars: mean+/-SD. (E) GC-derived B cell line were cultured in low serum concentration in the presence of neutrophils with or without (Ctrl) TACI-Fc. B-cell survival was evaluated by determining the percentage of DAPI ${ }^{\text {neg }} \mathrm{CD} 19 /$ $\mathrm{CD} 20^{\text {pos }} \mathrm{CD} 66 \mathrm{~b}^{\text {neg }}$ viable B cells at day 3, and compared to that of B cells cultured with PN without TACI-Fc, arbitrary assigned to $100 \%$. Results represent the mean \pm SD from 3 experiments. (F) Purified B cells sorted from 4 DLBCL and 4 FL LN were cultured in the presence or not of neutrophils. B-cell death was evaluated by determining the percentage of TOPRO- $3^{\text {pos }} \mathrm{CD} 19 / \mathrm{CD} 20^{\text {pos }} \mathrm{CD} 66 \mathrm{~b}^{\text {neg }} \mathrm{B}$ cells at day 1 for DLBCL and day 3 for FL and compared to that of B cells cultured alone, arbitrary assigned to $100 \%$. Bars: median. 
neutrophils, unlike malignant $\mathrm{B}$ cells, constitutively express significant amounts of TNFRSF13B/BAFF and TNFRSF13/APRIL (Figure 1D) and, in our co-culture experiments, simultaneous blockade of BAFF and APRIL activity by TACI-Fc significantly reduced the malignant B-cell supportive effect of neutrophils suggesting a role for membrane-bound molecules (Figure 1E). Finally, we explored the direct effect of neutrophils on primary malignant B cells obtained from FL and DLBCL including the two major molecular subtypes have been defined in this disease, the GC B cell-like (GCB) and the non-GCB DLBCL that differ by their response to chemotherapy and cure rate [29]. Interestingly, we were able to confirm the survival effect of neutrophils on B cells purified from 2 GCB and 2 non-GCB DLBCL samples, but not on 4 FL samples (Figure 1F).

To further investigate this discrepancy, and since APRIL-expressing TAN have been described as intermingled with DLBCL B cells [27], we decided to check by immunofluorescence the presence of neutrophils in invaded FL LN compared to chronically inflamed tonsils. The number of CD15 $5^{\text {pos }}$ cells is high and rather similar in inflamed and malignant samples. Most importantly, neutrophils remained essentially restricted to interfollicular and perifollicular zones, suggesting limited direct contact with malignant B cells but potential interactions with transglutaminase-expressing fibroblastic reticular cells (FRC), a lymphoid stromal cell subset recently involved in the survival of malignant FL B cells and in the homeostasis of normal B cells $[11,17$, 30] (Supplemental Figure S1). Collectively, these data demonstrated that neutrophils could directly support in vitro DLBCL malignant B-cell growth and raised the question of their indirect effect through the crosstalk with lymphoid stroma in FL.

\section{Infiltrating stromal cells recruit neutrophils and protect them from apoptosis}

IL-8 is the major neutrophil recruiting chemokine and is overexpressed by malignant cells in several solid tumors [3]. Strikingly, whereas neither GC-derived B cell lines nor FL and DLBCL primary B cells secreted IL-8 (data not shown), IL-8 was significantly increased in FL-invaded BM plasma compared with normal BM plasma (202.4 pg/mL [7.5-20.000] vs 17.9 pg/mL [7.554.2]; Figure 2A). We have previously demonstrated that FL-MSCs displayed a specific GEP making them a useful tool to study lymphoma-driven alterations of stromal microenvironment [11]. As described for CCL2, IL-8 was produced at a higher level in the supernatant of BM FL-MSCs, known to be ectopically committed to lymphoid stroma [11], compared with BM HD-MSCs (Figure 2B). We next tried to evaluate whether malignant B cells could contribute to this overexpression of IL-8 by FL-MSCs. For that purpose, HD-MSCs were cultured with TNF/LT, a well-known inducer of lymphoid stroma differentiation [17], or with primary FL B cells and RL cell line. This experiment revealed an increase in IL-8 secretion in the presence of malignant B cells (Figure 2C). Finally, we explored the functional relevance of such IL-8 induction and pinpointed that conditioned media from HD-MSCs treated by TNF/LT or primed by malignant B cells recruited more efficiently purified neutrophils than unstimulated HD-MSC supernatant (Figure 2D).

BM-MSCs were recently reported to support neutrophil survival in vitro $[7,8]$. We validated here this result by demonstrating a significant increase in the number of viable neutrophils after 2 to 4 days of culture in the presence of BM-MSCs. Moreover, we extended these data to tonsil-derived Resto stromal cells (Figure 2E). This supportive activity was associated with a decrease in neutrophil apoptosis (Figure 2F). Of note, similar results were obtained with HD-MSCs and FL-MSCs (Supplemental Figure S2). These data indicated that although lymphoma-infiltrating stromal cells produced higher levels of IL-8, probably in part through contact with malignant B cells, various stromal cell subsets could trigger neutrophil survival.

\section{Neutrophils and stromal cells cooperate to trigger malignant B-cell growth}

Since BM and tonsil-derived stromal cells triggered neutrophil recruitment and survival, we decided to test the tripartite co-culture between stromal cells, neutrophils, and $B$ cells.

Neutrophils cooperated with both HD-MSCs and Resto cells to promote the growth of malignant B-cell lines (Figure 3A-3B). As previously reported, treatment of stromal cells with TNF/LT reinforced their B-cell supportive capacity through commitment into functional lymphoid stroma [17]. Interestingly, combination of neutrophils and TNF/LT-stimulated stromal cells also improved B-cell growth compared to neutrophils or activated stromal cells alone. Since neutrophils were not able to directly sustain FL B-cell growth in vitro but were found in close contact with FL lymphoid stromal cells in situ, we tested how neutrophil/stromal cell cooperation could favor primary FL B-cell survival. Importantly, neutrophils increased the anti-apoptotic activity of both resting and TNF/LT-pretreated stromal cells towards purified FL B cells (Figure 3C), suggesting that such crosstalk could favor the organization of a fully supportive FL cell niche. 


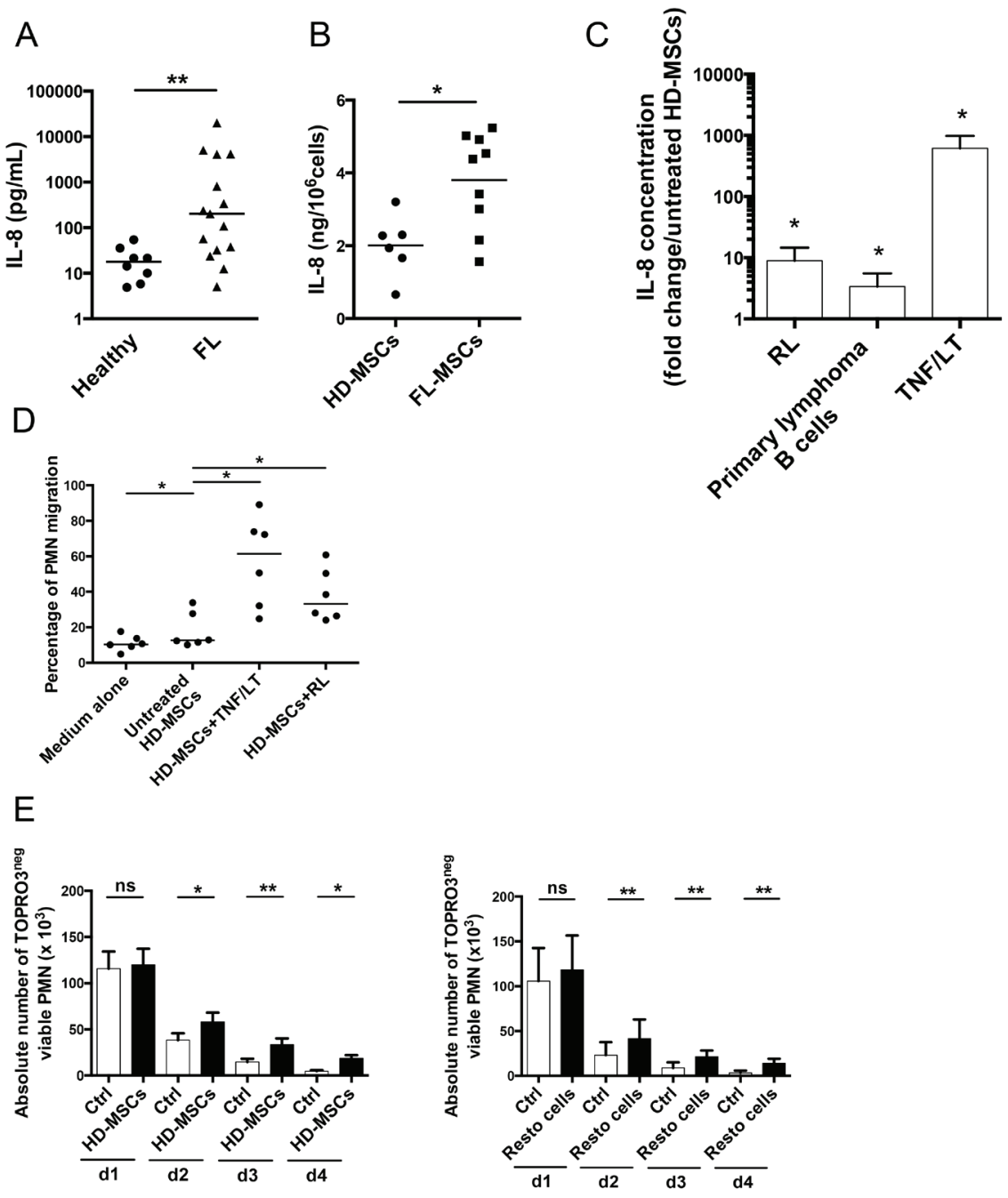

$\mathrm{F}$

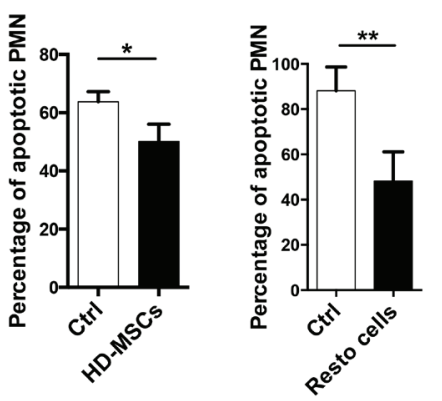

Figure 2: Infiltrating stromal cells recruit neutrophils and protect them from apoptosis. (A) IL-8 was quantified by ELISA in the BM plasma obtained from $\mathrm{HD}(\mathrm{n}=8)$ and FL patients $(\mathrm{n}=15)$. ${ }^{* *} P<0.01$. (B) IL-8 production in culture supernatants from HDMSCs ( $\mathrm{n}=6)$ and FL-MSCs $(\mathrm{n}=9)$ was quantified by ELISA at the end of P1. Data are normalized by the number of cultured MSCs. * $P<$ 0.05. (C) HD-MSCs were stimulated for 3 days by TNF/LT $(n=5)$ or were co-cultured with RL $(\mathrm{n}=6)$, or with purified primary FL B cells $(\mathrm{n}=6)$. IL-8 was measured in cell supernatants by ELISA. Results are expressed as the mean fold change \pm SD compared with untreated HD-MSCs. ${ }^{*} P<0.05$ (D) Migration of neutrophils (PMN) in response to medium alone, supernatants of HD-MSCs stimulated or not by TNF/LT for 3 days, or supernatants of HD-MSCs maintained during 3 days in coculture with RL. The percentage of neutrophil migration is calculated as the number of TOPRO- ${ }^{\text {neg }} \mathrm{CD} 66 \mathrm{~b}^{\text {pos }}$ viable neutrophils migrating in response to cell supernatant divided by their initial number. Results represent the mean \pm SD from 6 experiments. ${ }^{*} P<0.05$. (E) Purified neutrophils were cultured alone (Ctrl), in the presence of HD-MSCs $\left(\mathrm{n}=6\right.$, left), or Resto cells $\left(\mathrm{n}=9\right.$, right). The absolute number of TOPRO- $3^{\text {neg }} \mathrm{CD} 66 \mathrm{~b}^{\text {pos }} \mathrm{CD} 105^{\text {neg }}$ viable neutrophils was assessed using FlowCount beads. ${ }^{*} P<0.05$; ${ }^{* *} P<0.01$. (F) Percentage of $C D 66 b^{\text {pos }} \mathrm{CD} 105^{\text {neg }}$ neutrophil apoptosis was evaluated at day 1 by the use of active caspase-3 staining for neutrophils cultured alone (Ctrl), in the presence of HD-MSCs ( $\mathrm{n}=6$, left), or Resto cells (n=9, right). $* P<.05 ; * * P<.01$ 

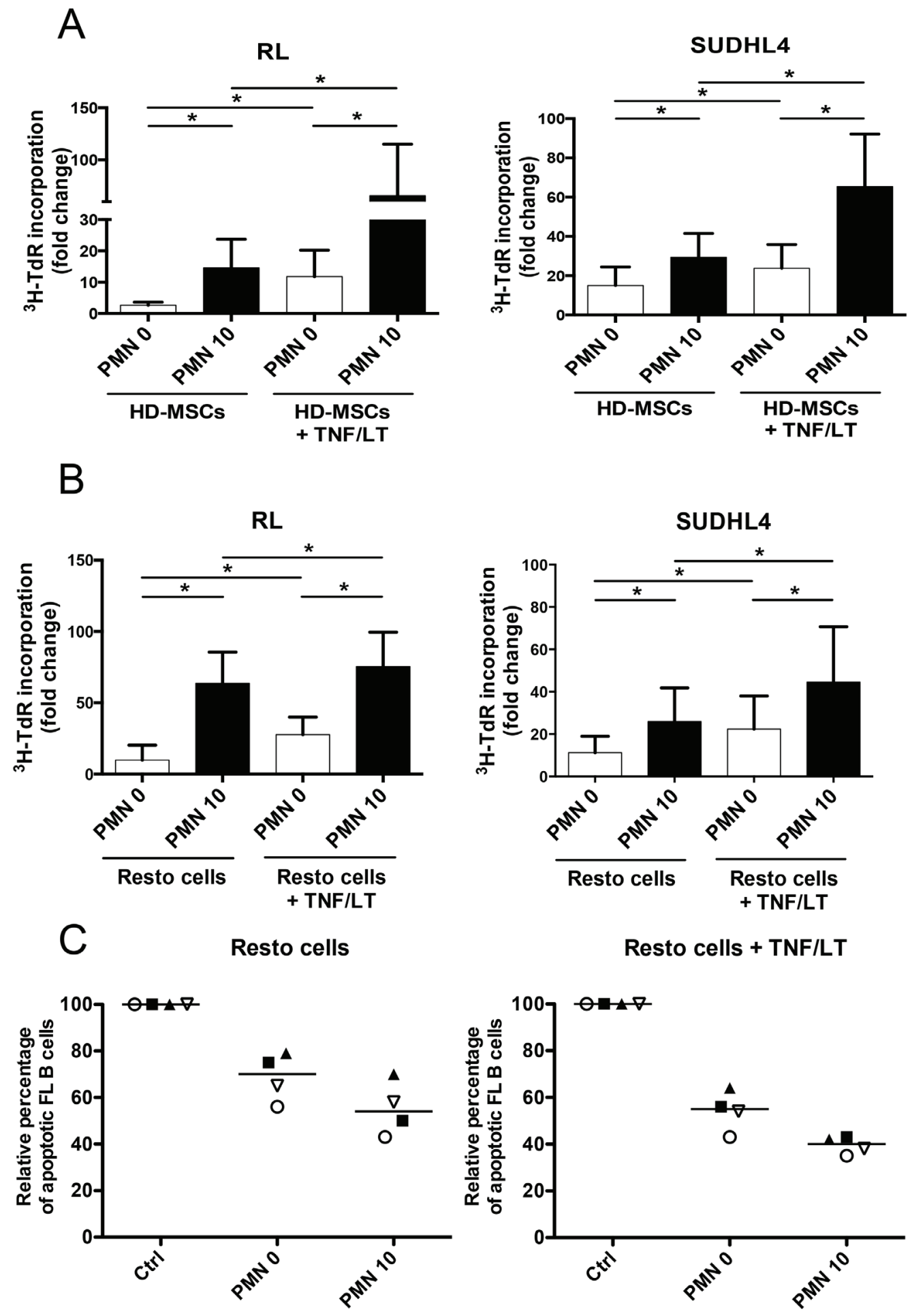

Figure 3: Neutrophils and stromal cells cooperate to sustain malignant B-cell growth. (A-B) GC-derived B-cell lines were cultured in low serum concentration with BM-MSCs (A) or tonsil Resto cells (B) in the presence or not of neutrophils (PMN). Stromal cells were pretreated or not with TNF/LT before co-culture. B-cell growth was evaluated by tritiated thymidine ( $\left.{ }^{3} \mathrm{H}-\mathrm{TdR}\right)$ incorporation at day 2 for RL and at day 3 for SUDHL4. Stromal cells cultured alone always showed a ${ }^{3} \mathrm{H}-\mathrm{TdR}$ incorporation $<500 \mathrm{cpm} .{ }^{3} \mathrm{HTdR}$ incorporation of B-cell alone was assigned to 1 . Results represent the mean \pm SD from 6 to 7 experiments. $* P<0.05$. (C) Purified FL B cells were cultured with or without (Ctrl) Resto cells in the presence or not of PMN. Resto cells were pretreated or not with TNF/LT before co-culture. B-cell apoptosis was evaluated by determining the percentage of active caspase- $3^{\text {pos }} \mathrm{CD} 19 / \mathrm{CD} 20^{\text {pos }} \mathrm{CD} 66 \mathrm{~b}^{\text {neg }} \mathrm{B}$ cells at day 2 and compared to that of FL B cells cultured alone, arbitrary assigned to $100 \%$. Each symbol corresponds to an individual patient sample. Bars: median. 


\section{Neutrophils drive stromal cells into a B-cell supportive inflammatory lymphoid stroma phenotype}

Neutrophil half-life is short compared to that of resident stromal cells in vivo, leading us to explore the hypothesis that neutrophils and stromal cells established a bidirectional crosstalk where neutrophils newly recruited by stromal cells contributed in turn to their polarization. Priming of stromal cells by neutrophils increased their capacity to further support B-cell growth at a similar level than activation by TNF/LT (Figure 4A). In addition, neutrophils exhibited a strong activity on TNF/LTconditioned stroma, mimicking FRC lymphoid cells, and converted them into highly powerful malignant B-cell supportive cells.

To understand the molecular basis of this neutrophildependent priming of stromal cells, we decided to study the GEP of both BM-MSCs and Resto cells after co-culture with neutrophils. Importantly, no residual neutrophil, as validated by RQ-PCR for the neutrophil specific gene ELANE, was detected in primed stromal cell samples after neutrophil removal. We underlined 3 signatures: the neutrophil-primed MSC signature comprising 964 probesets (PS), the neutrophil-primed Resto signature comprising 1152 PS, and the neutrophil-primed stroma signature obtained by comparing the 6 unprimed stromal cell samples to the 6 neutrophil-primed stromal cell samples and comprising 577 PS (Supplemental Tables S1-S3). Among the 151 PS that were simultaneously found with in the neutrophil-primed MSC signature and the neutrophil-primed Resto signature (Figure 4B), 134 were coordinately up-regulated or down-regulated (Supplemental Table S4).

We next performed gene set enrichment analysis (GSEA) approach based on previously published signatures to highlight the major pathways activated by neutrophils in stromal cells. Interestingly, neutrophilprimed MSCs and Resto cells showed signs of lymphoid stroma polarization and inflammatory response, with a strong activation of TNF and NF- $\mathrm{KB}$ signaling pathways (Figure 4C-4H). Among the most strongly up-regulated genes in neutrophil-primed stromal cells we selected a set of 5 genes previously described as overexpressed in human lymphoid stromal cells $[11,31]$ (Table 1) and confirmed the significant overexpression of $I L-8, I L-6$, CCL2, PTGS2/COX-2, and ICAM by RQ-PCR in both neutrophil-primed MSCs and neutrophil-primed Resto cells (Supplemental Figure S3A). Accordingly, we demonstrated that stromal cells primed with neutrophils for 3 days before neutrophil removal and maintained again in culture for 3 days secreted significantly higher levels of IL-8 (6.4-fold for MSCs and 3.8-fold for Resto cells), IL-6 (2.9-fold for MSCs and 3.5-fold for Resto cells), CCL2 (1.5-fold for MSCs and 1.5-fold for Resto cells), and PGE2 (6.5-fold for MSCs and 1.9-fold for Resto cells) than their unstimulated counterparts (Figure 5A). They also displayed a stronger membrane expression of CD54 (4-fold for MSCs and 6-fold for Resto cells). To definitively conclude on the lymphoid stroma polarization of neutrophil-primed stromal cells, we checked for their capacity to secrete and organize a meshwork of transglutaminase-positive fibers and to express podoplanin/gp38, two well-described markers of human FRCs. Neutrophil-primed stromal cells produced a dense transgutaminase-positive extracellular reticular network with a very similar pattern to that obtained following FRCcommitment by TNF/LT [17], and expressed high levels of podoplanin (Figure 5B). Of note, as previously reported after TNF/LT-mediated activation [17], transglutaminase expression was not regulated at the transcriptional level in stromal cells by neutrophils (data not shown). However, $P D P N$ was significantly induced in both MSCs and Resto cells after priming by neutrophils (Supplemental Figure S3B).

We next sought to determine whether these neutrophil-primed FRC-like cells became fully competent not only as tumor B-cell feeders, but also as organizers of lymphoma B-cell niche. We decided to focus on monocyte and neutrophil migration since FL-MSCs have been shown to recruit both cell subsets more efficiently than HDMSCs. We first revealed that supernatants of neutrophilprimed MSCs and Resto cells triggered an improved chemotaxis of monocytes and neutrophils, compared to resting stromal cells (Figure 5C). To ascertain whether CCL2 and IL-8 contributed to stroma-dependent myeloid cell migration, we specifically depleted them from stromal cell conditionned media. Interestingly, CCL2 and IL-8 depletion strongly decreased monocyte and neutrophil recruitment, respectively.

Taken together, these results support the hypothesis that neutrophil-primed stromal cells were engaged toward lymphoid stroma differentiation, in association with an increased capacity to support malignant B-cell growth and to trigger monocyte and neutrophil recruitment.

\section{Neutrophil-dependent stroma polarization is associated with $\mathrm{NF}-\kappa \mathrm{B}$ activation and NETosis}

Since the GEP of neutrophil-activated stromal cells revealed enrichment for genes belonging to NF- $\kappa B$ and TNF signaling pathways, we decided to evaluate the role of NF- $\mathrm{KB}$ activation and TNF in neutrophildependent stroma polarization. We validated that TNFR1Fc completely abrogated the upregulation of $I L-8$ and CCL2 induced by addition of exogeneous TNF (data not shown). Interestingly, inhibition of IKK by wedelolactone, unlike the specific blockade of TNFR1, strongly reduced the neutrophil-mediated induction of $I L-8$ and CCL2 in stromal cells (Figure 6A). 

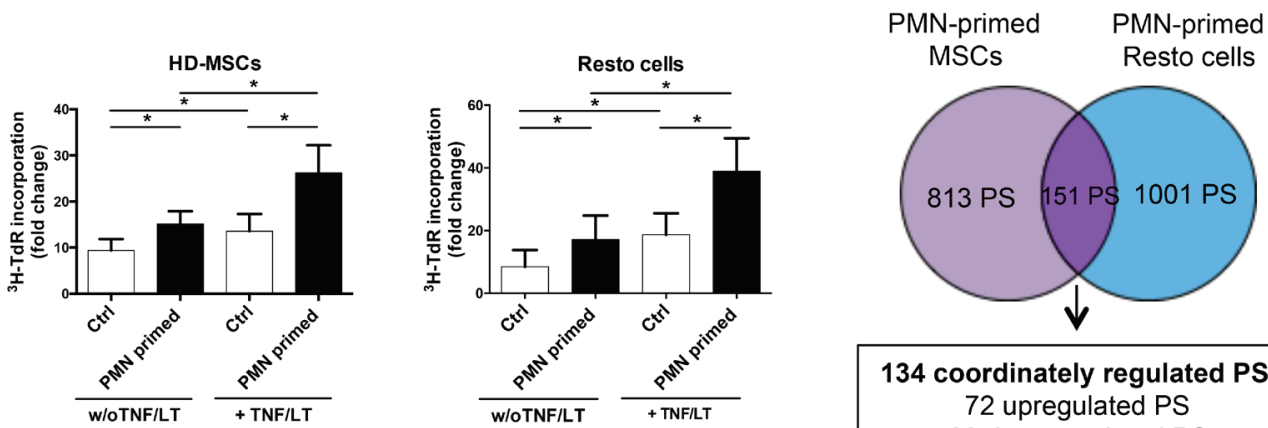

\section{4 coordinately regulated PS: \\ 72 upregulated PS}

62 downregulated PS
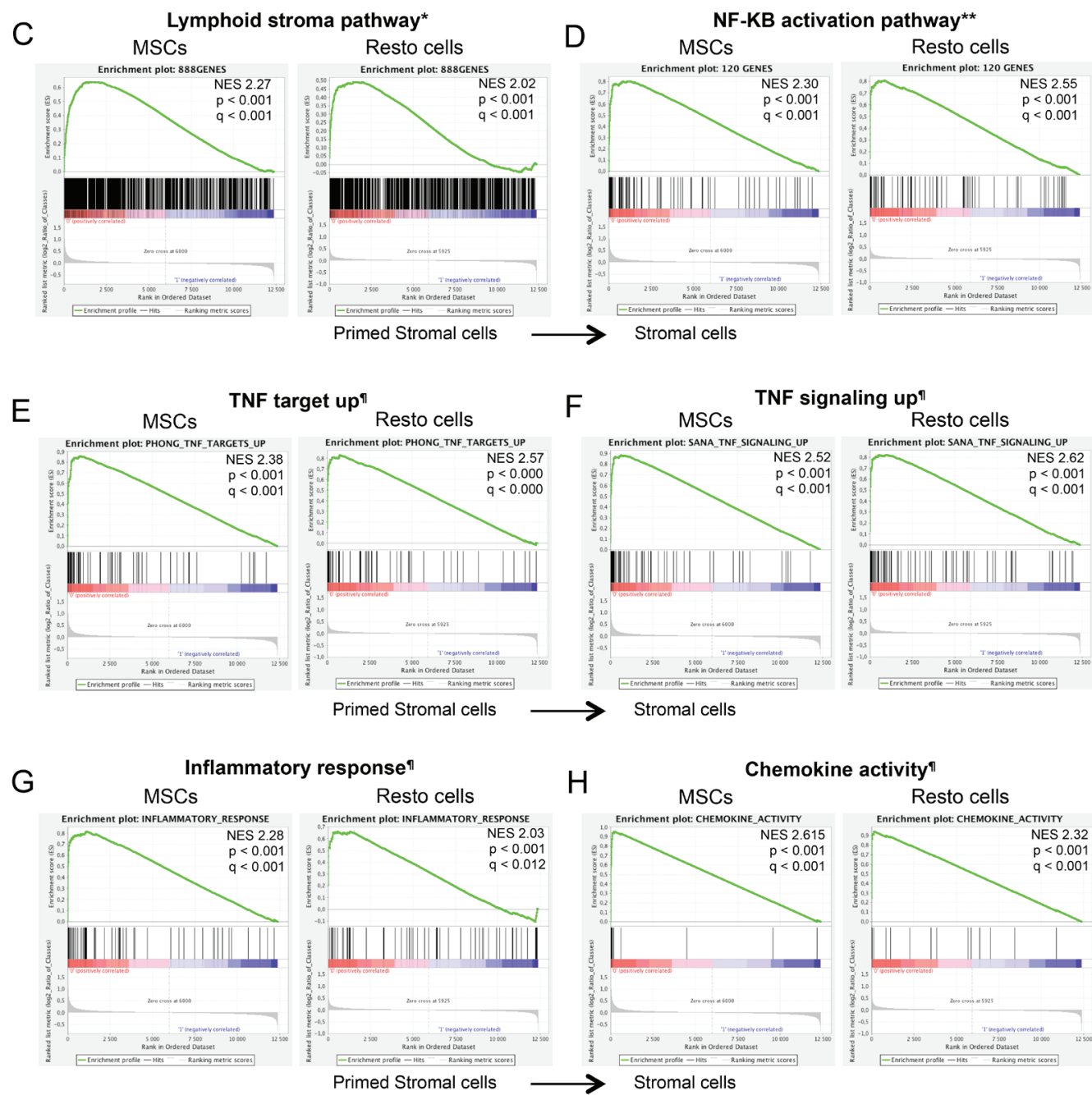

$\mathrm{H}$
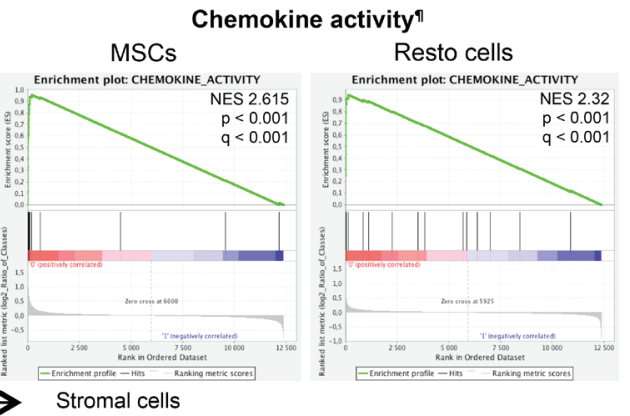

Figure 4: Neutrophils induce a specific B-cell supportive inflammatory profile in stromal cells. (A) RL cell line was cultured in low serum concentration in the presence of BM-MSCs or tonsil Resto cells primed or not (Ctrl) by neutrophils (ratio stromal cells/neutrophils: 1:1.5) and/or TNF/LT before co-culture. RL cell growth was evaluated by tritiated thymidine $\left({ }^{3} \mathrm{H}-\mathrm{TdR}\right)$ incorporation at day 2. Stromal cells cultured alone always showed a ${ }^{3} \mathrm{H}-\mathrm{TdR}$ incorporation $<500 \mathrm{cpm} .{ }^{3} \mathrm{HTdR}$ incorporation of B-cell alone was assigned to 1 . Results represent the mean \pm SD from 6 experiments. ${ }^{*} P<0.05$. (B) Schematic representation of the statistical analysis used to highlight the minimal neutrophil-primed stromal cells signature defined as the intersection of the 2 gene lists obtained for neutrophil-primed MSCs (964 probesets) and neutrophil-primed Resto cells (1152 probesets) by paired $t$-test (absolute $\log _{2}$ fold change $>1.2$ and $P<0.05$ ). (C-H) Selected plots from a GSEA based on the comparison of neutrophil-primed versus unprimed stromal cell signatures. Normalized enrichment score (NES), nominal $p$-value (p), and FDR (q) are given for each plot. Primed stromal cells are shown on the left (red) of the plots, normal stromal cells on the right side (blue). * TNF/LT lymphoid stroma signature [11], ** NF-kB target gene set [53], "MySigDB gene set (GSEA software). 

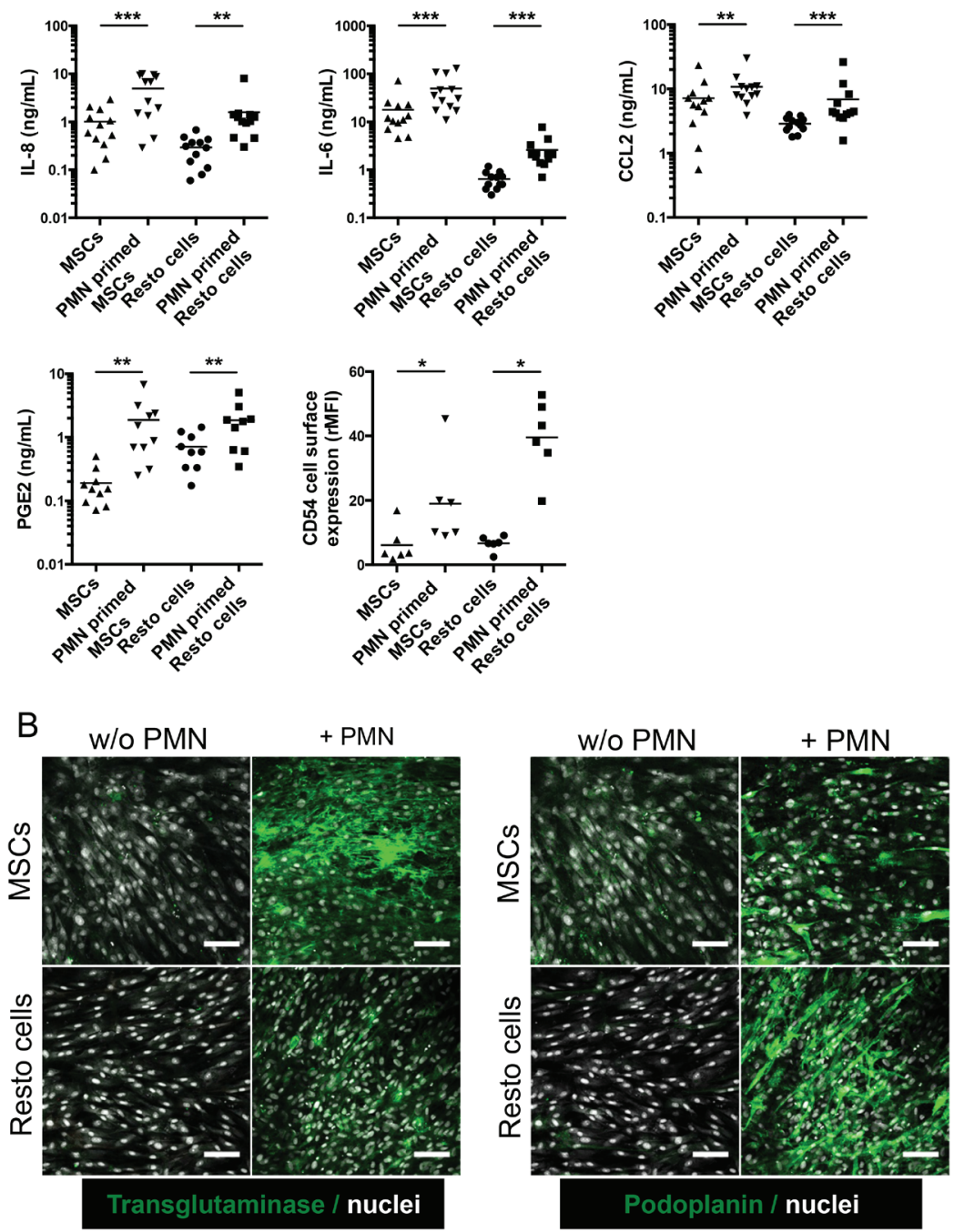

C
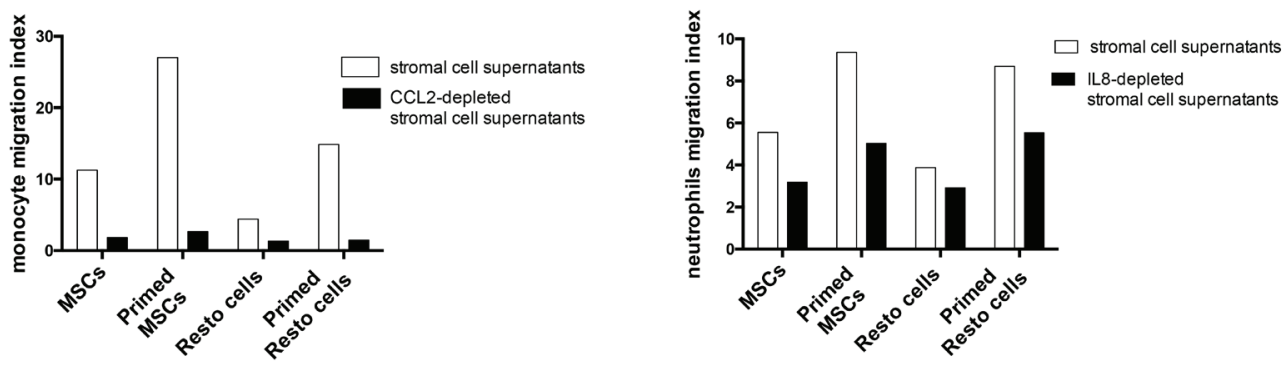

Figure 5: Functional validation of the inflammatory lymphoid stroma phenotype triggered by neutrophils in stromal cells. (A) Production of IL-8, IL-6, CCL2, and PGE2 was evaluated by ELISA in the supernatant of stromal cells primed or not with neutrophils (PMN) for 3 days before neutrophil removal and additional 3-day culture of stromal cells alone ( $\mathrm{n}=10$ to 12). CD54 expression was evaluated by flow cytometry on stromal cells primed or not with neutrophils as the ratio of mean fluorescence intensity (rMFI) compared with isotype control. * $P<0.05$; ${ }^{*} P<.001$; $* * * P<0.001$. (B) Stromal cells were cultured for 3 days with or without neutrophils before fixation and transglutaminase and podoplanin staining. Scale bars, $100 \mu \mathrm{m}$. (C) Migration of purified peripheral blood monocytes (left) or neutrophils (right) in response to supernatants of stromal cells primed or not with neutrophils and specifically depleted or not from CCL2 or IL-8 with magnetic beads. Cell migration index is calculated as the number of DAPI ${ }^{\text {neg }} \mathrm{CD} 14^{\text {pos }}$ (monocytes) or DAPI ${ }^{\text {neg }} \mathrm{CD}^{\text {p6 }} \mathrm{b}^{\text {pos }}$ (neutrophils) viable cells migrating in response to cell supernatant divided by their numbers in response to migration medium. Shown is one representative experiment out of 3 . 
Table 1: Expression of lymphoid stromal cell genes in primed versus unprimed stromal cell subsets.

\begin{tabular}{|c|c|c|c|c|c|c|}
\hline \multirow{2}{*}{ Gene Symbol } & \multicolumn{2}{|c|}{ Primed MSCs } & \multicolumn{2}{c|}{ Primed Resto cells } & \multicolumn{2}{c|}{ Primed stromal cells $^{\S}$} \\
\cline { 2 - 7 } & P-value & Fold Change* & P-value & Fold Change* & $\boldsymbol{P}_{\text {-value }}$ & Fold Change* $^{*}$ \\
\hline IL8 & 0.027 & 205.7 & 0.011 & 114.6 & $6.64 \mathrm{e}-005$ & 153.6 \\
\hline & & & & & & \\
\hline IL6 & $\mathrm{ns}(0.058)$ & 7.1 & 0.029 & 17.4 & 0.006 & 11.1 \\
\hline & & & & & & \\
\hline CCL2 & 0.006 & 7.8 & 0.046 & 7.2 & 0.002 & 7.5 \\
\hline PTGS2 & & & & & & \\
\hline & $\mathrm{ns}(0.150)$ & 7.4 & 0.021 & 2.7 & 0.021 & 4.0 \\
\hline ICAM1 & 0.013 & 16.7 & 0.004 & 30.7 & $1.49 \mathrm{e}-005$ & 14.2 \\
\hline & & & & & & \\
\hline
\end{tabular}

* Fold Change corresponds to the ratio of median expression in neutrophil-primed / unprimed stroma

$\S$ Primed stromal cells represent the data obtained by comparing the group of neutrophil-primed MSCs and Resto cells to the group of unprimed MSCs and Resto cells

A

IL-8

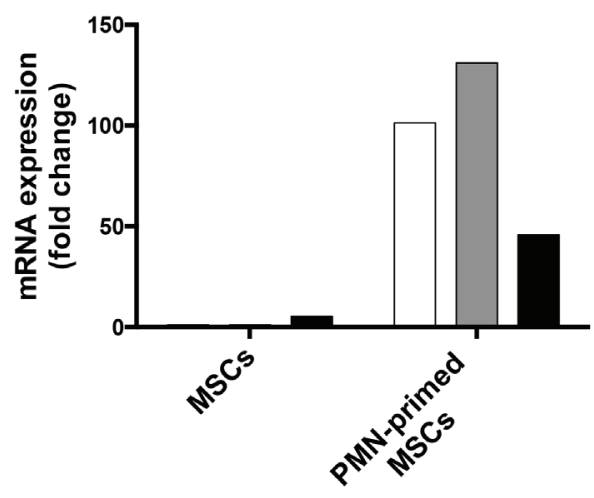

CCL2

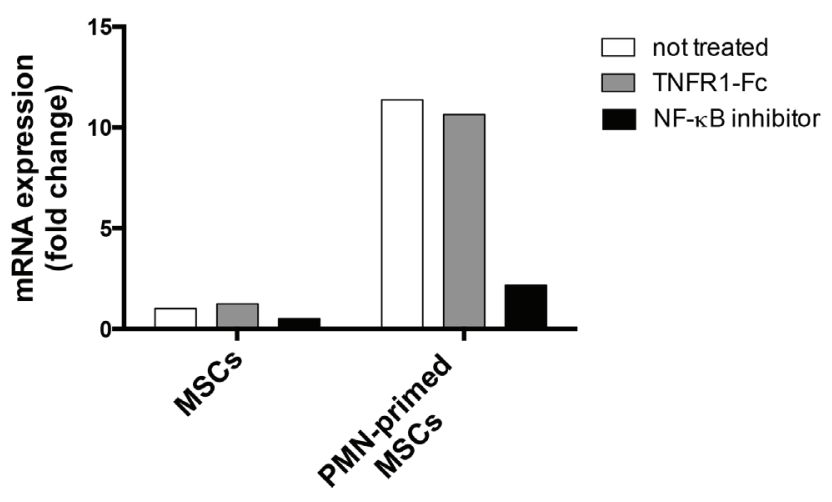

B

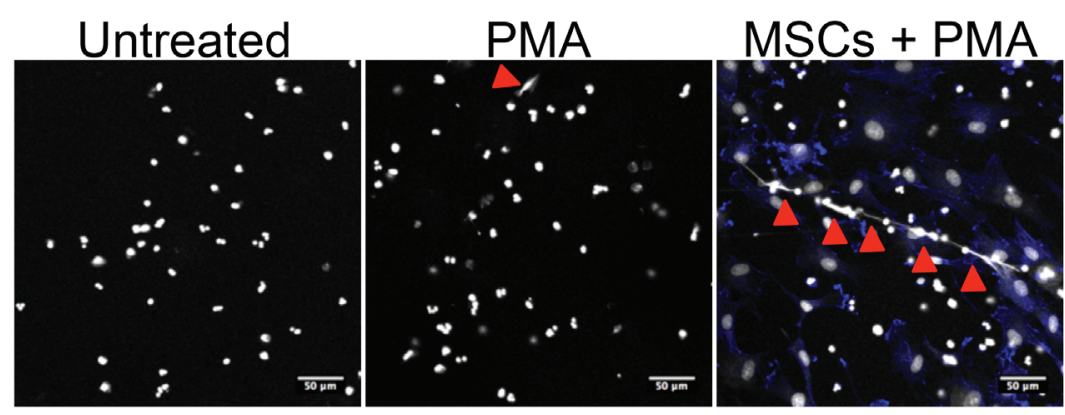

Actin / DNA

Figure 6: NF-אB pathway is involved in neutrophil-dependent stromal cell priming. (A) MSCs were cultured with TNFR1Fc or wedelolactone in the presence or not of neutrophils (PMN) for 1 day and RQ-PCR was performed on stromal cells to analyze IL8, and CCL2 expression. Each sample was normalized to PUM1 expression and compared to expression levels in untreated MSCs.Shown is one representative experiment out of 3. (B) Neutrophils were cultured with or without MSCs for $12 \mathrm{~h}$ and thereafter treated or not for $3 \mathrm{~h}$ with PMA before staining of actin with phalloidin (blue) and DNA with Sytox (white). Arrows indicate NET formation. Scale bars, $50 \mu \mathrm{m}$. 
Recently, neutrophils were reported to trigger NF- $\kappa \mathrm{B}$ activation in $\mathrm{CD}^{\mathrm{pos}} \mathrm{B}$ cells in a mouse model of chronic lymphocytic leukemia and this activation relied on their capacity to undergo NETosis [32]. We thus tested whether MSCs could influence NETosis. For that purpose, freshly isolated neutrophils were seeded onto poly-D-lysine (a permissive substrate for NET) and stimulated by a low dose of PMA, a well-known NET inducer. Interestingly, whereas MSCs did not directly promote NET formation, they favored PMA-triggered NETosis (Figure 6B).

\section{DISCUSSION}

In this paper, we highlighted for the first time both direct and indirect tumor promoting effects of neutrophils in GC-derived B-cell lymphomas, a group of diseases in which TAN have been poorly studied even if microenvironment is supposed to play a key role. We first extended a previous work revealing that neutrophilderived APRIL is concentrated within DLBCL cell niches [27] by showing that neutrophils could favor DLBCL B-cell growth in vitro, in a BAFF/APRIL dependent manner. We could not detect any activity of soluble exogenous BAFF or APRIL on malignant B cells and direct neutrophil/B-cell contact was required. Since APRIL, unlike BAFF, requires concentration and aggregation by heparan sulfate proteoglycans to be active and is poorly detected in DLBCL peripheral blood samples despite a high concentration at the TAN/B-cell interface inside tumors [27], it is tempting to speculate that APRIL plays a preeminent role over BAFF in this system, thus arguing for the development of APRIL antagonist mAbs for the treatment of B-cell lymphomas [33].

In FL samples, we could not detect a direct effect of neutrophils on B-cell survival but neutrophils and stromal cells cooperate to inhibit FL B-cell apoptosis. FL-TAN exhibited essentially perifollicular localization in close contact with FRC, raising the question of the recruitment and role of these peritumoral neutrophils that have been proposed as promoters of angiogenesis in hepatocellular carcinomas [34]. Interestingly, FRC meshwork is expanded and activated within FL-invaded $\mathrm{LN}$, and FL BM infiltration is characterized by the ectopic development of lymphoid-like stromal cells that form aggregates with malignant B cells [16]. The mechanisms underlying such activation of tumor-infiltrating stroma remain incompletely understood. We have previously demonstrated that FL-MSCs overexpressed CCL2 in response to B-cell derived TNF [11] and identified here IL- 8 as another marker of tumor-educated MSCs. These data argue for a crucial role for malignant cells in stroma activation. Of note, PGE2 is also produced at higher level by FL-infiltrating stromal cells in LN and BM but the mechanism of this overexpression is unknown [35]. Importantly, CCL2, IL-8, and PGE2 were all induced by the crosstalk between neutrophils and stromal cells.
Moreover, neutrophils were able to convert tonsil and BM-derived stromal cells into lymphoid stroma with transcriptomic, phenotypic, and functional features of FRC-like cells, a property that has been only described until now for lymphoid precursors, some mature CD4 $4^{\text {pos }}$ $\mathrm{T}$ cells, and malignant $\mathrm{B}$ cells $[17,36,37]$. These results suggest that non-malignant cells, in particular TAN, contribute to the acquisition of lymphoma-specific stroma features, as recently proposed in gastric cancer, where neutrophils favor the transition of MSCs towards CAF-like cells promoting gastric cell migration [9]. Conversely, as already reported for BM-MSCs [7, 8], we confirmed that LN and BM stromal cells support survival of neutrophils. Besides this anti-apoptotic activity, CAFs have been recently demonstrated to activate neutrophils in both solid tumors and lymphoid malignancies. In particular, based on a genetically-induced remodeling of LN stroma in autoimmune prone mice, an elegant study has underlined how stromal cells could trigger lymphoma transformation by increasing TAN activation [32]. Moreover, such reshaping of stroma architecture, induced by a loss of expression of the extracellular matrix protein SPARC, was detected in situ in early-stage FL, suggesting that neutrophil/stromal cell/B cell tripartite interactions take place within FL cell niche.

The molecular mechanisms of the neutrophilmediated stroma activation clearly involved NF- $\mathrm{B}$ pathway, as highlighted by the transcriptomic analysis, and by the inhibition of CCL2 and IL- 8 expression by IKK inhibitor. It has long been assumed that NF- $\kappa B$ is the central effector of lymphoid stroma differentiation in normal and pathological settings [36]. More surprisingly, blockade of TNFR1 did not abrogate the effect of neutrophils on stromal cells, suggesting that other NF- $\mathrm{BB}-$ activating molecules could be involved. As an example, neutrophils have been described to express functional CD40L [23] whereas CD40 is detected on inflammatory stromal cells [38]. However, neutrophils also induced a strong expression of TNF in stromal cells (data not shown) and such autocrine loop is very difficult to inhibit by blocking antibodies. We could thus not exclude an involvement of stroma-derived TNF in the lymphoid stroma differentiation process. Another interesting observation was that stromal cells sensitized neutrophils to activation-induced NETosis. NET formation has been associated with the capacity of neutrophils to activate $\mathrm{NF}-\kappa \mathrm{B}$ pathway in chronic lymphocytic leukemia B cells [32]. It is thus tempting to speculate that NET also contributes to neutrophil-mediated activation of NF- $\kappa \mathrm{B}$ in stromal cells. Activated platelets were recently reported to simultaneously protect neutrophils from apoptosis and prime them for NET through expression of HMGB1 [39]. How stromal cells favor both neutrophil survival and extrusion of NET is a key unsolved issue.

Bidirectional crosstalk between stromal cells and neutrophils has several tumor-promoting functional 
consequences. First, neutrophil-primed stromal cells supported more efficiently the growth of malignant B cells, a property shared with stromal cells committed towards lymphoid stroma by TNF/LT or by co-culture with malignant B cells [17]. We previously demonstrated that stromal cells and macrophages synergized to promote lymphoma cell growth [11] and our current data reveal that such cell collaboration is also effective between stromal cells and neutrophils. Second, neutrophil-primed stromal cells produced high amounts of CCL2 and IL-8 that triggered monocyte and neutrophil recruitment, respectively. Multiple lines of evidence support a role for TAM in the biology of GC-derived lymphoma, in particular through their capacity to produce BAFF and IL-15 [40, 41]. A high number of STAT1 ${ }^{\text {pos }}$ FL-TAM is associated with an adverse outcome [42] and STAT1 activation triggers CCR2 induction in macrophages [43] thus favoring their recruitment by stromal CCL2. Neutrophils could thus contribute to the stroma/ macrophage crosstalk. Moreover, CCL2, IL-8, and PGE2 have been shown to inhibit neutrophil apoptosis $[3,44]$. Finally, neutrophils could also participate to the development of an immunosuppressive microenvironment in B-cell lymphomas. TGF- $\beta$ is overexpressed in B-cell lymphomas and contributes to effector memory $\mathrm{T}$ cell exhaustion [45]. TGF- $\beta$ is usually sequestered as an inactive complex, and becomes activated through enzymes and reactive oxygen free radicals, all produced by activated neutrophils [3]. Besides IL-8, several other ligands of CXCR2, including CXCL1, CXCL3, and CXCL5, were induced by neutrophils in stromal cells whereas macrophage migration inhibitory factor (MIF) expression was not modulated. Interestingly, CXCL5 is also upregulated during lymphoid stroma differentiation [11]. These chemokines could thus contribute to the stroma-dependent migration of neutrophils that was only partly inhibited by IL-8-depletion. Altogether, neutrophils display a wide range of tumor-supporting activity through their interaction with stromal cells and this crosstalk should be considered, in addition to the previously characterized TAM/stroma crosstalk, for the design of new therapeutic strategies.

One of the most interesting feature of FL-TAM is their opposite predictive value depending on the treatment schedule. In fact, FL-TAM could favor tumor progression but also contribute to the clinical efficacy of antibody-based anti-lymphomadrugs [14]. Whether such dual activity exists for lymphoma-infiltrating neutrophils has not been precisely explored. However, besides the well-known roles of NK and macrophages in anti-CD20 antibody activity, neutrophils have already been shown to contribute to the antitumor efficacy of Rituximab [46] and more recently of obinutuzumab through CD16Bdependent phagocytosis [47]. In addition, anti-CD20 IgA have been proposed as highly efficient alternative to classical IgG1 in particular through their capacity to trigger lymphoma cell phagocytosis by CD89-expressing neutrophils [48]. Finally, both GM-CSF and G-CSF, two neutrophil growth factors, have been suggested to improve rituximab efficacy in relapsed/refractory low-grade lymphoma patients $[49,50]$. A better understanding of the role of TAN in the intricate network of cell interactions that drives B-cell lymphoma survival, growth, and drug resistance/sensitivity is a highly relevant issue with potential clinical consequences for the design of new antilymphoma approaches.

\section{MATERIALS AND METHODS}

\section{Patient samples and cell lines}

Samples came from subjects recruited under institutional review board approval and informed consent process according to the Declaration of Helsinki. BM aspirates were obtained from FL patients at diagnosis and age-matched patients undergoing cardiac surgery, tonsils from children undergoing routine tonsillectomy, LN biopsies from FL and DLBCL patients, and peripheral blood (PB) from adult healthy volunteers. $\mathrm{BM}$ plasma were collected by centrifugation and frozen until use. BM-MSCs and tonsil-derived stromal cells (Resto) were obtained as previously described [11, 17] and used for functional studies at passages 1 to 3 and 8 to 15 ; respectively. Peripheral blood (PB) neutrophils, $\mathrm{PB}$ monocytes, and malignant $\mathrm{B}$ cells from frozen $\mathrm{FL}$ and DLBCL biopsies were purified using whole blood CD15 microbeads, monocyte isolation kit II, and B-cell isolation kit II (Miltenyi Biotech), respectively. Purified cell fractions with at least $98 \%$ cell purity as evaluated by flow cytometry were used for further experiments. GC-derived lymphoma B-cell lines RL, SUDHL4, and DOHH2 were obtained from the DSMZ. Classification of DLBCL samples into GCB versus non-GCB subtypes was performed as described [51].

\section{Antibodies and flow cytometry}

FITC-conjugated monoclonal antibodies (mAbs) to CD14, CD19, CD20, and CD66b; PE-conjugated mAbs to CD19, CD20, CD54, and CD105; PC7-conjugated mAbs to CD19, and CD20; and PB-conjugated mAbs to CD15 were provided by Beckman Coulter. Alexa-647cojugated mAb to CD105 was provided by ebioscience. Appropriate isotype-matched mAbs were used as negative controls and all analyses were performed using a Gallios (Beckman Coulter) flow cytometer.Cell death was checked using TOPRO-3 or DAPI (Life Technologies) staining. Apoptosis evaluation was performed using PE-conjugated active caspase-3 apoptosis kit (Becton Dickinson). 


\section{B-cell growth and apoptosis}

After serum deprivation, RL and SUDHL4 were seeded with low serum concentration in the presence of purified neutrophils and/or on a confluent stromal cell monolayer. B-cell growth was evaluated by tritiated thymidine incorporation or by counting the number of viable B cells using FlowCounts beads (Beckman Coulter). B-cell apoptosis was analyzed by the use of active caspase-3 staining. When indicated, neutrophils and B cells were separated by a $0.4-\mu \mathrm{m}$ pore Transwell filter or were co-cultured in the presence of polyclonal human immunoglobulin (Tegeline ${ }^{\circledR}$, LFB Biomedicaments) and TACI-Fc inhibitor (100 ng/mL, R\&D Systems). Stromal cells were pretreated with TNF- $\alpha$ (TNF, $20 \mathrm{ng} / \mathrm{mL})$ and lymphotoxin- $\alpha 1 \beta 2$ (LT, $100 \mathrm{ng} / \mathrm{mL}$; R\&D Systems) and/ or primed with neutrophils before washing and co-culture with B cells. For primary lymphoma samples, purified malignant $\mathrm{B}$ cells were seeded in the presence or not of stromal cells and/or neutrophils before analysis of B-cell death.

\section{Cytokine quantification}

IL-8 was quantified by ELISA (R\&D Systems) in BM plasma, in the supernatants of HD-MSCs and FL-MSCs collected at the end of passage 1, and in the supernatants of HD-MSCs stimulated with TNF/LT or cocultured with RL or purified FL B cells for 3 days. In addition, we measured by ELISA IL-8, IL-6, CCL2 (R\&D Systems) and PGE2 (Cayman Chemical) levels in the supernatants of stromal cells primed or not by neutrophils for 3 days before neutrophil removal and additional 3-day culture period. To confirm the stromal origin of secreted cytokines after priming with neutrophils, we checked by RQ-PCR that the mRNA level of ELANE, the neutrophil-specific elastase coding gene, was negative after neutrophil removal. When indicated, inhibitors of NF- $\kappa \mathrm{B}$ pathway were used during the priming of stromal cells by neutrophils, including TNFR1-Fc $(100 \mathrm{ng} / \mathrm{mL}$, R\&D Systems) or wedelolactone (50 $\mu \mathrm{M}$, Calbiochem). The dose of wedelolactone was chosen as efficient to inhibit NF- $\mathrm{KB}$ signaling [52] without any cytotoxic effect on stromal cells.

\section{Migration assays}

Purified PB neutrophils or monocytes $\left(10^{5}\right.$ cells $/ 100 \mu \mathrm{L}$ ) were added in RPMI- $0.1 \%$ human serum albumin (neutrophil migration medium) or RPMI-1\% FCS (monocyte migration medium) to the upper compartment of Transwell chambers with $5-\mu \mathrm{m}$ pore filters. Lower chambers contained supernatants of stromal cells obtained after 3 days of priming by TNF/LT, RL, or neutrophils. For
IL-8 and CCL2 depletion, 2.10 Dynabeads pan mouse IgG (Life Technologies) were conjugated to $10 \mu \mathrm{g}$ anti-IL-8 or anti-CCL2 mAbs (R\&D Systems) before incubation with supernatants. Supernatants were thereafter seeded inside a magnetic field to allow immune complex retention. We checked by ELISA that IL- 8 or CCL2 were undetectable in corresponding depleted supernatants. Conversely, the use of an isotype-matched control mAb did not modify the concentration of IL-8 or CCL2. The absolute number of DAPI ${ }^{\text {neg }}{ }^{2}$ D66 $b^{\text {pos }}$ viable neutrophils or DAPI ${ }^{\text {neg }} \mathrm{CD} 14^{\text {pos }}$ viable monocytes was quantified using FlowCount beads in the lower chamber after 1 and 2 hours, respectively.

\section{Neutrophil survival and apoptosis}

Purified neutrophils were cultured alone or in the presence of stromal cells. Cell apoptosis was analyzed using active caspase-3 staining gated on $\mathrm{CD}^{2} 6 \mathrm{~b}^{\mathrm{pos}} \mathrm{CD} 105^{\text {neg }}$ neutrophils, and the number of TOPRO- $3^{\text {neg }} \mathrm{CD} 66 \mathrm{~b}^{\text {pos }} \mathrm{CD} 105^{\text {neg }}$ viable neutrophils was determined each day for 4 days.

\section{Gene expression profiling (GEP) study}

GEP was performed on 3 HD-MSCs and 3 tonsilderived Resto cells primed or not with neutrophils for 1 day (ratio 1:1.5). RNA was extracted after neutrophils removal by extensive washes, using RNeasy Mini Kit, (Qiagen) and the purity and integrity of RNA were checked with the Bioanalyzer 2100 (Agilent Technologies). We checked for the absence of residual neutrophils by RQ-PCR for ELANE. Biotinylated cRNA were amplified according to the IVT express labeling protocol and hybridized on GeneChip HG-U133 Plus2 oligonucleotide microarrays (Affymetrix). Microarray data were deposited at NCBI GEO data set under accession number GSE62782. Data were analyzed with the Partek Genomics Suite (Partek). Expression signal values and $P$-values were obtained for each probeset (PS) using the Partek Genomics Suite software (Partek) after normalization by Robust Multichip Averaging algorithm with GC content adjustment (GC-RMA). Background noise was decreased by eliminating PS with a low standard deviation to mean ratio. To compare stromal cells primed or not by neutrophils, supervised analysis were carried out by paired Student $t$-test with Partek Genomics Suite software allowing the selection of PS with absolute $\log _{2}$ fold change $>1.2$ and an adjusted $P$-value less than 0.05 . Gene Set Enrichment Analysis (GSEA) software was used to determine the specific enrichment of specific gene sets in the PMN-primed stroma signatures. 


\section{Real-time quantitative PCR}

An additional set of neutrophil-stromal cell coculture experiments was performed for validation of GEP data and RNA was generated from resting and neutrophil-primed stromal cells. cDNA synthesis was performed with the Superscript II reverse transcriptase and random hexamers (Life Technologies). For quantitative RQ-PCR, we used assay-on-demand primers and probes, and Taqman Universal Master Mix (Life Technologies). Gene expression was measured using the StepOnePlus (Life Technologies) based on the $\Delta \mathrm{C}_{\mathrm{t}}$ calculation method. PUM1 was determined as the appropriate internal standard gene using TaqMan Endogenous Control Assays (Life Technologies). Quantification of TNFRSF13 and TNFRSF13B was performed using appropriate assay-ondemand primers and probes and $A B L 1$ as internal standard gene in GC B-cell lines, purified CD14 ${ }^{\text {pos }}$ monocytes, and purified $\mathrm{CD} 15^{\text {pos }}$ neutrophils. For each sample, the $\mathrm{Ct}$ value for the gene of interest was determined, normalized to its respective value for $A B L 1$, and results were then standardized by comparison to gene expression of a pool of five whole tonsil cells.

\section{Immunofluorescence}

BM-MSCs and Resto cells were seeded on chamber coverslips and cultured with or without neutrophils for 3 days before neutrophil removal by extensive washes and staining for transglutaminase and podoplanin [17]. Cells were fixed in $2 \%$ paraformaldehyde-PBS and stained with antibodies against transglutaminase and podoplanin (Abcam) followed by labeling with anti-mouse Alexa 488 and anti-rat Alexa 594 secondary antibodies (Jackson Immunoresearch). Coverslips were mounted with mowiol mounting medium including Sytox blue (Life Technologies) and examined using a confocal microscope (SP5X, Leica Microsystem) equipped with a $40 \mathrm{x}$ oil objective. Digital images were processed using ImageJ software.

For NET formation, purified neutrophils were seeded onto slides coated with poly-D-lysine or HD-MSC monolayer for 12 hours before stimulation for 3 hours with $20 \mathrm{ng} / \mathrm{ml}$ PMA (Sigma-Aldrich). Cells were fixed with $4 \%$ paraformaldehyde-PBS and stained with Texas Red-X Phalloidin (Life Technologies). Coverslips were mounted with mowiol mounting medium including Sytox blue and examined using a confocal microscope.

\section{Statistical analyses}

Statistical analyses were performed with GraphPad Prism 6.0 software using the non-parametric Wilcoxon test for matched pairs or the Mann-Whitney nonparametric $U$ test as appropriate.

\section{ACKNOWLEDGMENTS}

Affymetrix microarrays were processed in the Microarray Core Facility of the Institute of Research on Biotherapy, CHRU-INSERM-UM1 Montpellier, http:// irb.chu-montpellier.fr/ and immunofluorescence study was performed on the Microscopy Rennes Imaging Center (MRic-ALMF; UMS 6480 Biosit, Rennes, France). The authors are indebted to the Centre de Ressources Biologiques (CRB)-Santé (BB-0033-00056, http://www. crbsante-rennes.com) of Rennes hospital for its support in the processing of biological samples, and Christophe Ruaux for providing tonsil samples.

\section{CONFLICTS OF INTEREST}

The authors declare no competing financial interest.

\section{GRANT SUPPORT}

This work was supported by research grants from the Ligue Nationale Contre le Cancer (Equipe Labellisée), the Association pour la Recherche Contre le Cancer (ARC AO 2011) and from the European Center for Transplantation Sciences and Immunotherapy (IHU CESTI, ANR-10IBHU-0005). M.G. is recipient of a doctoral fellowship from the Ligue Nationale Contre le Cancer, the Région Bretagne (ARED), and ARC.

\section{Editorial note}

This paper has been accepted based in part on peerreview conducted by another journal and the authors' response and revisions as well as expedited peer-review in Oncotarget.

\section{REFERENCES}

1. Mantovani A, Cassatella MA, Costantini C and Jaillon S. Neutrophils in the activation and regulation of innate and adaptive immunity. Nature reviews Immunology. 2011; 11:519-531.

2. Scapini P and Cassatella MA. Social networking of human neutrophils within the immune system. Blood. 2014; 124:710-719.

3. Sionov RV, Fridlender ZG and Granot Z. The Multifaceted Roles Neutrophils Play in the Tumor Microenvironment. Cancer microenvironment: official journal of the International Cancer Microenvironment Society. 2014.

4. Sparmann A and Bar-Sagi D. Ras-induced interleukin-8 expression plays a critical role in tumor growth and angiogenesis. Cancer cell. 2004; 6:447-458. 
5. Dumitru CA, Fechner MK, Hoffmann TK, Lang S and Brandau S. A novel p38-MAPK signaling axis modulates neutrophil biology in head and neck cancer. Journal of leukocyte biology. 2012; 91:591-598.

6. Ohlund D, Elyada E and Tuveson D. Fibroblast heterogeneity in the cancer wound. The Journal of experimental medicine. 2014; 211:1503-1523.

7. Raffaghello L, Bianchi G, Bertolotto M, Montecucco F, Busca A, Dallegri F, Ottonello L and Pistoia V. Human mesenchymal stem cells inhibit neutrophil apoptosis: a model for neutrophil preservation in the bone marrow niche. Stem Cells. 2008; 26:151-162.

8. Cassatella MA, Mosna F, Micheletti A, Lisi V, Tamassia N, Cont C, Calzetti F, Pelletier M, Pizzolo G and Krampera M. Toll-like receptor-3-activated human mesenchymal stromal cells significantly prolong the survival and function of neutrophils. Stem Cells. 2011; 29:1001-1011.

9. Zhu Q, Zhang X, Zhang L, Li W, Wu H, Yuan X, Mao F, Wang M, Zhu W, Qian H and Xu W. The IL-6-STAT3 axis mediates a reciprocal crosstalk between cancer-derived mesenchymal stem cells and neutrophils to synergistically prompt gastric cancer progression. Cell death \& disease. 2014; 5:e1295.

10. Sant M, Allemani C, Tereanu C, De Angelis R, Capocaccia R, Visser O, Marcos-Gragera R, Maynadie M, Simonetti A, Lutz JM and Berrino F. Incidence of hematologic malignancies in Europe by morphologic subtype: results of the HAEMACARE project. Blood. 2010; 116:3724-3734.

11. Guilloton F, Caron G, Menard C, Pangault C, AmeThomas P, Dulong J, De Vos J, Rossille D, Henry C, Lamy T, Fouquet O, Fest T and Tarte K. Mesenchymal stromal cells orchestrate follicular lymphoma cell niche through the CCL2-dependent recruitment and polarization of monocytes. Blood. 2012; 119:2556-2567.

12. Dave SS, Wright G, Tan B, Rosenwald A, Gascoyne RD, Chan WC, Fisher RI, Braziel RM, Rimsza LM, Grogan TM, Miller TP, LeBlanc M, Greiner TC, Weisenburger DD, Lynch JC, Vose J, et al. Prediction of survival in follicular lymphoma based on molecular features of tumor-infiltrating immune cells. The New England journal of medicine. 2004; 351:2159-2169.

13. Lenz G, Wright G, Dave SS, Xiao W, Powell J, Zhao H, $\mathrm{Xu} \mathrm{W}$, Tan B, Goldschmidt N, Iqbal J, Vose J, Bast M, $\mathrm{Fu} \mathrm{K}$, Weisenburger DD, Greiner TC, Armitage JO, et al. Stromal gene signatures in large-B-cell lymphomas. The New England journal of medicine. 2008; 359:2313-2323.

14. Ame-Thomas $\mathrm{P}$ and Tarte $\mathrm{K}$. The yin and the yang of follicular lymphoma cell niches: role of microenvironment heterogeneity and plasticity. Seminars in cancer biology. 2014; 24:23-32.

15. Scott DW and Gascoyne RD. The tumour microenvironment in B cell lymphomas. Nature reviews Cancer. 2014; 14:517534.

16. Mourcin F, Pangault C, Amin-Ali R, Ame-Thomas P and
Tarte K. Stromal cell contribution to human follicular lymphoma pathogenesis. Frontiers in immunology. 2012; $3: 280$.

17. Ame-Thomas P, Maby-El Hajjami H, Monvoisin C, Jean R, Monnier D, Caulet-Maugendre S, Guillaudeux T, Lamy $\mathrm{T}$, Fest $\mathrm{T}$ and Tarte K. Human mesenchymal stem cells isolated from bone marrow and lymphoid organs support tumor B-cell growth: role of stromal cells in follicular lymphoma pathogenesis. Blood. 2007; 109:693-702.

18. Lwin T, Crespo LA, Wu A, Dessureault S, Shu HB, Moscinski LC, Sotomayor E, Dalton WS and Tao J. Lymphoma cell adhesion-induced expression of B cellactivating factor of the TNF family in bone marrow stromal cells protects non-Hodgkin's B lymphoma cells from apoptosis. Leukemia. 2009; 23:170-177.

19. He B, Chadburn A, Jou E, Schattner EJ, Knowles DM and Cerutti A. Lymphoma B cells evade apoptosis through the TNF family members BAFF/BLyS and APRIL. J Immunol. 2004; 172:3268-3279.

20. Gupta M, Dillon SR, Ziesmer SC, Feldman AL, Witzig TE, Ansell SM, Cerhan JR and Novak AJ. A proliferationinducing ligand mediates follicular lymphoma B-cell proliferation and cyclin D1 expression through phosphatidylinositol 3-kinase-regulated mammalian target of rapamycin activation. Blood. 2009; 113:5206-5216.

21. Scapini P, Bazzoni F and Cassatella MA. Regulation of B-cell-activating factor (BAFF)/B lymphocyte stimulator (BLyS) expression in human neutrophils. Immunology letters. 2008; 116:1-6.

22. Holden NJ, Williams JM, Morgan MD, Challa A, Gordon J, Pepper RJ, Salama AD, Harper L and Savage CO. ANCAstimulated neutrophils release BLyS and promote B cell survival: a clinically relevant cellular process. Annals of the rheumatic diseases. 2011; 70:2229-2233.

23. Puga I, Cols M, Barra CM, He B, Cassis L, Gentile M, Comerma L, Chorny A, Shan M, Xu W, Magri G, Knowles DM, Tam W, Chiu A, Bussel JB, Serrano S, et al. B cell-helper neutrophils stimulate the diversification and production of immunoglobulin in the marginal zone of the spleen. Nature immunology. 2012; 13:170-180.

24. Nagelkerke SQ, aan de Kerk DJ, Jansen MH, van den Berg TK and Kuijpers TW. Failure to detect functional neutrophil B helper cells in the human spleen. PloS one. 2014; 9:e88377.

25. Gorlino CV, Ranocchia RP, Harman MF, Garcia IA, Crespo MI, Moron G, Maletto BA and Pistoresi-Palencia MC. Neutrophils exhibit differential requirements for homing molecules in their lymphatic and blood trafficking into draining lymph nodes. J Immunol. 2014; 193:1966-1974.

26. Beauvillain C, Cunin P, Doni A, Scotet M, Jaillon S, Loiry ML, Magistrelli G, Masternak K, Chevailler A, Delneste $\mathrm{Y}$ and Jeannin P. CCR7 is involved in the migration of neutrophils to lymph nodes. Blood. 2011; 117:1196-1204.

27. Schwaller J, Schneider P, Mhawech-Fauceglia P, McKee 
T, Myit S, Matthes T, Tschopp J, Donze O, Le Gal FA and Huard B. Neutrophil-derived APRIL concentrated in tumor lesions by proteoglycans correlates with human B-cell lymphoma aggressiveness. Blood. 2007; 109:331-338.

28. Porrata LF, Ristow K, Habermann T, Inwards DJ, Micallef IN and Markovic SN. Predicting survival for diffuse large B-cell lymphoma patients using baseline neutrophil/ lymphocyte ratio. American journal of hematology. 2010; 85:896-899.

29. Alizadeh AA, Eisen MB, Davis RE, Ma C, Lossos IS, Rosenwald A, Boldrick JC, Sabet H, Tran T, Yu X, Powell JI, Yang L, Marti GE, Moore T, Hudson J, Jr., Lu L, et al. Distinct types of diffuse large B-cell lymphoma identified by gene expression profiling. Nature. 2000; 403:503-511.

30. Cremasco V, Woodruff MC, Onder L, Cupovic J, NievesBonilla JM, Schildberg FA, Chang J, Cremasco F, Harvey CJ, Wucherpfennig K, Ludewig B, Carroll MC and Turley SJ. B cell homeostasis and follicle confines are governed by fibroblastic reticular cells. Nature immunology. 2014; 15:973-981.

31. Kim J, Lee S, Kim YM, Jeoung DI and Choe J. Human follicular dendritic cells promote germinal center B cell survival by providing prostaglandins. Molecular immunology. 2013; 55:418-423.

32. Sangaletti S, Tripodo C, Vitali C, Portararo P, Guarnotta C, Casalini P, Cappetti B, Miotti S, Pinciroli P, Fuligni F, Fais F, Piccaluga PP and Colombo MP. Defective stromal remodeling and neutrophil extracellular traps in lymphoid tissues favor the transition from autoimmunity to lymphoma. Cancer discovery. 2014; 4:110-129.

33. Guadagnoli M, Kimberley FC, Phan U, Cameron K, Vink PM, Rodermond H, Eldering E, Kater AP, van Eenennaam $\mathrm{H}$ and Medema JP. Development and characterization of APRIL antagonistic monoclonal antibodies for treatment of B-cell lymphomas. Blood. 2011; 117:6856-6865.

34. Kuang DM, Zhao Q, Wu Y, Peng C, Wang J, Xu Z, Yin XY and Zheng L. Peritumoral neutrophils link inflammatory response to disease progression by fostering angiogenesis in hepatocellular carcinoma. Journal of hepatology. 2011; 54:948-955.

35. Gallouet AS, Travert M, Bresson-Bepoldin L, Guilloton F, Pangault C, Caulet-Maugendre S, Lamy T, Tarte K and Guillaudeux T. COX-2-independent effects of celecoxib sensitize lymphoma B cells to TRAIL-mediated apoptosis. Clinical cancer research : an official journal of the American Association for Cancer Research. 2014; 20:2663-2673.

36. Katakai T, Hara T, Sugai M, Gonda H and Shimizu A. Lymph node fibroblastic reticular cells construct the stromal reticulum via contact with lymphocytes. The Journal of experimental medicine. 2004; 200:783-795.

37. Koning JJ and Mebius RE. Interdependence of stromal and immune cells for lymph node function. Trends in immunology. 2012; 33:264-270.

38. Franco G, Guarnotta C, Frossi B, Piccaluga PP, Boveri E,
Gulino A, Fuligni F, Rigoni A, Porcasi R, Buffa S, Betto E, Florena AM, Franco V, Iannitto E, Arcaini L, Pileri SA, et al. Bone marrow stroma CD40 expression correlates with inflammatory mast cell infiltration and disease progression in splenic marginal zone lymphoma. Blood. 2014; 123:1836-1849.

39. Maugeri N, Campana L, Gavina M, Covino C, De Metrio M, Panciroli C, Maiuri L, Maseri A, D’Angelo A, Bianchi ME, Rovere-Querini $\mathrm{P}$ and Manfredi AA. Activated platelets present High Mobility Group Box 1 to neutrophils, inducing autophagy and promoting the extrusion of neutrophil extracellular traps. J Thromb Haemost. 2014; 12:2074-88.

40. Epron G, Ame-Thomas P, Le Priol J, Pangault C, Dulong J, Lamy T, Fest T and Tarte K. Monocytes and T cells cooperate to favor normal and follicular lymphoma B-cell growth: role of IL-15 and CD40L signaling. Leukemia. 2012; 26:139-148.

41. Mueller CG, Boix C, Kwan WH, Daussy C, Fournier E, Fridman WH and Molina TJ. Critical role of monocytes to support normal B cell and diffuse large B cell lymphoma survival and proliferation. Journal of leukocyte biology. 2007; 82:567-575.

42. Alvaro T, Lejeune M, Camacho FI, Salvado MT, Sanchez L, Garcia JF, Lopez C, Jaen J, Bosch R, Pons LE, Bellas $\mathrm{C}$ and Piris MA. The presence of STAT1-positive tumorassociated macrophages and their relation to outcome in patients with follicular lymphoma. Haematologica. 2006; 91:1605-1612.

43. Hu X, Park-Min KH, Ho HH and Ivashkiv LB. IFN-gammaprimed macrophages exhibit increased CCR2-dependent migration and altered IFN-gamma responses mediated by Stat1. J Immunol. 2005; 175:3637-3647.

44. Yang EJ, Choi E, Ko J, Kim DH, Lee JS and Kim IS. Differential effect of CCL2 on constitutive neutrophil apoptosis between normal and asthmatic subjects. Journal of cellular physiology. 2012; 227:2567-2577.

45. Yang ZZ, Grote DM, Xiu B, Ziesmer SC, Price-Troska TL, Hodge LS, Yates DM, Novak AJ and Ansell SM. TGFbeta upregulates CD70 expression and induces exhaustion of effector memory $\mathrm{T}$ cells in B-cell non-Hodgkin's lymphoma. Leukemia. 2014; 28:1872-1884.

46. Hernandez-Ilizaliturri FJ, Jupudy V, Ostberg J, Oflazoglu E, Huberman A, Repasky E and Czuczman MS. Neutrophils contribute to the biological antitumor activity of rituximab in a non-Hodgkin's lymphoma severe combined immunodeficiency mouse model. Clinical cancer research : an official journal of the American Association for Cancer Research. 2003; 9:5866-5873.

47. Golay J, Da Roit F, Bologna L, Ferrara C, Leusen JH, Rambaldi A, Klein C and Introna M. Glycoengineered CD20 antibody obinutuzumab activates neutrophils and mediates phagocytosis through CD16B more efficiently than rituximab. Blood. 2013; 122:3482-3491.

48. Pascal V, Laffleur B, Debin A, Cuvillier A, van Egmond 
M, Drocourt D, Imbertie L, Pangault C, Tarte K, Tiraby $\mathrm{G}$ and Cogne M. Anti-CD20 IgA can protect mice against lymphoma development: evaluation of the direct impact of IgA and cytotoxic effector recruitment on CD20 target cells. Haematologica. 2012; 97:1686-1694.

49. Cartron G, Zhao-Yang L, Baudard M, Kanouni T, Rouille V, Quittet P, Klein B and Rossi JF. Granulocytemacrophage colony-stimulating factor potentiates rituximab in patients with relapsed follicular lymphoma: results of a phase II study. Journal of clinical oncology : official journal of the American Society of Clinical Oncology. 2008; 26:2725-2731.

50. van der Kolk LE, Grillo-Lopez AJ, Baars JW and van Oers MH. Treatment of relapsed B-cell non-Hodgkin's lymphoma with a combination of chimeric anti-CD20 monoclonal antibodies (rituximab) and G-CSF: final report on safety and efficacy. Leukemia. 2003; 17:1658-1664.

51. Hans CP, Weisenburger DD, Greiner TC, Gascoyne RD, Delabie J, Ott G, Muller-Hermelink HK, Campo E, Braziel RM, Jaffe ES, Pan Z, Farinha P, Smith LM, Falini $\mathrm{B}$, Banham AH, Rosenwald A, et al. Confirmation of the molecular classification of diffuse large B-cell lymphoma by immunohistochemistry using a tissue microarray. Blood. 2004; 103:275-282.

52. Tattevin P, Monnier D, Tribut O, Dulong J, Bescher N, Mourcin F, Uhel F, Le Tulzo Y and Tarte K. Enhanced indoleamine 2,3-dioxygenase activity in patients with severe sepsis and septic shock. The Journal of infectious diseases. 2010; 201:956-966.

53. Compagno M, Lim WK, Grunn A, Nandula SV, Brahmachary M, Shen Q, Bertoni F, Ponzoni M, Scandurra M, Califano A, Bhagat G, Chadburn A, Dalla-Favera $\mathrm{R}$ and Pasqualucci L. Mutations of multiple genes cause deregulation of NF-kappaB in diffuse large B-cell lymphoma. Nature. 2009; 459:717-721. 